\title{
DYNAMICS IN DIAGNOSING THE QUALITY OF THE GOOD TEACHER
}

\author{
M. Teneva* \\ Faculty of Education, Trakia University, Stara Zagora, Bulgaria
}

\begin{abstract}
Education is a supreme human value that builds on the prosperity of society and the development of world progress. The personality of the teacher has a significant influence on the results of the educational process. The genesis of the teaching profession is rooted in ancient times. Over the centuries it has marked its development and affirmed its socially meaningful nature. Practising the profession of "teacher" is based on a person-to-person interaction. It is seen as a well-structured system with clearly differentiated and hierarchical levels of interaction. In his or her professional activity, the teacher enters into different interactions and realizes a complex of functions and professional roles, on the basis of which different types of teachers can be differentiated. One type of teacher is flexible, adaptable, open-minded, conscientious, creative, active, patient, committed to the profession, spiritualized, supporting the child's development, ready to accept challenges. The other type is the conservative teacher, biased, irresponsible, reproductive, unbalanced, selfish, unconcerned for the prosperity of the students, boring, applying templates in their work. The first mentioned type of teachers receive a high public score for their professional work. They are categorized by users of educational services as good teachers. The second type of the so indicated teacher has a low public score for their work. They are categorized by users of educational services as bad, unloved teachers. What qualities are needed to be a good teacher? Which personal and professional qualities are highly valued for practising the teaching profession? These questions provoked our research attention to diagnosing the qualities of a good teacher. The subject of the study is the qualities of the good teacher. The aim of the study is to differentiate such personal and professional qualities that are characteristic of good teachers.

Methods of research: pedagogical study, test, content analysis, correlation analysis, range scaling.

Contingent of the study: The survey was conducted in 2017. It includes 128 respondents. 64 students from pedagogical specialties and 64 practicing teachers were included in the study. Results: The results indicate that there is a correlational dependence between three, from the differentiated to be in the first five positions, qualities of the good teacher. Students from the pedagogical majors and practitioners are solidarized around the belief that love for children, love for the profession and patience are the qualities that are most often met in the good teachers. It is these qualities that occupy a leading position in the rank scale of the teacher's prominent qualities, composed by the two target groups of respondents.
\end{abstract}

Key words: education, teaching profession, qualities of the good teacher

\section{INTRODUCCTION}

The teaching profession is characterized by its ancient origins. It has evolved over the centuries to become today's modern and extremely important for the prosperity of society profession. The school as a social institution is called upon to fulfill a number of valuable for the society functions aimed at the education and prosperity of the adolescent and young person. Some of them are in line with

\footnotetext{
*Correspondence to: Maria Teneva

Faculty of Education, Trakia University - Stara

Zagora, Bulgaria,m.s.teneva@abv.bg
}

the ideas of full intellectual development of the students in the process of education, with the preparation for their social functioning as active members of civil society, their adequate professional orientation and their preparation for successful realization on the labor market. These responsible tasks, which are placed before the educational system, could not be realized without the active purposeful activity in this direction of the practising teachers. It is of utmost importance what the people are who educate the future generations of the creators of the human progress. Some teachers love their profession, they are ready to devote 
themselves to the pedagogical interaction with the children in order to realize their noble mission and receive high public appraisal for their highly professional work. Others, with annoyance and dislike, wait for the class to end in order to distance themselves from their students. The first type is characterized as good teachers and enjoys the love of their students. The second type is characterized as bad teachers with whom students do not want to interact. For us it is a scientific interest to determine with what qualities the character of the good teacher is characterized in order to emphasize in the course of the academic training of the students of the pedagogical specialties the formation and development of these valuable professional qualities.

\section{METHODOLOGY OF THE RESEARSH}

The object of the study is the teaching profession.

The subject of the study is the qualities of the good teacher.

The aim of the study is to differentiate the dynamics in the diagnosis of personal and professional qualities that are characteristic of good teachers.

Methods of research: pedagogical study, test, content analysis, correlation analysis, range scaling.

Contingent of the study: The survey was conducted in 2017. It includes 128 respondents. 64 students from pedagogical specialties studying at the Faculty of Pedagogy of Trakia University - Stara Zagora were involved and 64 practising teachers who teach in primary schools in the southeast region of Bulgaria. Thirty-two of them teach at the primary-school stage and thirty-two in the lower secondary stage of the primary education.

The study is exhaustive and does not claim representation but would help to highlight the dynamics of diagnosing the teacher's prominent qualities.

Research toolkit: For the purposes of the study, a test called "Diagnostic qualities of a good teacher" was used created by G. Sabine and published in "Experimental Pedagogy" by D. Vassilev (1). The test was provided for anonymous replenishment. All respondents are asked to indicate their gender. We asked students to indicate their age and the teachers to indicate their pedagogical experience in years. The results of Task 1 of the test were used to diagnose the teacher's proficiency. In Task 1 respondents are required to rank (from
TENEVA $M$.

1 to 22) the significance of a predefined list containing a set of 22 qualities, with 1 . highlighting the most significant, and with 22. the lowest in importance according to them quality that the teacher must possess. This gives us the opportunity to extract from the list those qualities that the respondents put most often in the leading positions, differentiating them as qualities of the greatest importance for the teaching profession. Using the frequency principle, we make a statistical sample of those qualities that are most often ranked from 1 to 5. These five qualities, in the order of their ranging, stand out as professional qualities of the teacher, registering the dynamics in diagnosing these qualities in the students and the practising teachers.

\section{DISCUSSION}

One of the most significant possessions that man possesses (along with consciousness and self-awareness) is the freedom they have and the ability to make independent decisions by which to manage their own life. As stated by R. Stamatov and B. Minchev: "The person is called to be free. Freedom of personality is not freedom from but freedom for "(2). In his conscious life, man is free to make a number of choices, some of which are so important that they can model his or her life. Such choices are often called "fateful". An important choice in the life of the modern man is the choice of profession. Factors influencing professional choices could be sought in several ways. Some of them relate to the characteristics of the person, to his or her inner biases and attitudes. Others closely correspond to the peculiarities of the environment and the social relationships created within it. Significant factors for professional choices can be pointed to be the needs of the person, his or her abilities and interests. "These key factors are in triadic dependence; they are designed on the motivation of the personality and model their behaviour". (3) His ideas about the free choice of a profession are presented and popularized by A. Soloviev (4). He presents in a schematic form a model for choosing a profession, which is characterized by three key factors - abilities, interests, labour market, among which several sections are observed. The author emphasizes the importance of three key sections influencing the choice of profession, namely: matching the interests and abilities of the personality, synchronizing personal and public interests and the possibility of free choice of profession (in line with the person's abilities); based on the possibility of realization on the 
labour market. A similar idea in the Bulgarian scientific literature is presented by D. Vassilev and Y. Merdjanova. The two authors consider that the choice of profession should be done according to 'the interests of the personality (defining its preferences and ambitions in the sector of what is desired); the abilities and qualities of the person (defining its features as opportunities and limitations in the sector of the available); the characteristics of the labor market and the profession - the objective context of the choice "(5). They argue that the decision to choose a profession must be taken on the basis of the three main groups of circumstances. Since it is difficult to meet the requirements of all three sectors, professional choices would have to be preceded by skillful professional guidance. Successful professional choice apart from the self-knowledge of the personality is also influenced in a positive aspect by the knowledge of the specifics of the particular profession. Interesting is the popularized classification of E. A. Klimov concerning the types of professions, based on the relationship of the person, who is perceived as the subject of labor, to the subject of labor. In this aspect, E.A. Klimov differentiates between five types of professions: man-nature, man-technology, man-man, man-sign system, man-artistic image (6). According to the author, the teaching profession should be attributed to the type of man-man occupations. This is a public profession whose practice requires the person to have an interpersonal interaction ability. When one knows his or her own self well, when they have discovered his strengths and personal deficits, when they have harmonized their needs, abilities and interests, they would successfully go down the path of their personal professional self-determination and make a successful professional choice. Regarding the modern type of person, M. Andreev puts the following questions: "What type of person is needed in society today? Is it "a person of a super-personal profession or we need a choice of profession according to the person's unique individuality" (7). Brad Olsen promotes his model of choice for the teaching profession. The author points out that the entrance and staying in the teaching profession is influenced by the professional identity. In his opinion, the views on the teacher's identity are the result of social psychology, philosophy and sociolinguistics. Based on a case study, the author identifies the factors that affect the teacher's professional identity. As such, he points out: previous personal experience, previous professional experience, conditions for entering the profession, the context of learning (8). Researchers in the field of the teaching profession unite around the idea of the multi-faceted realization of teacher interactions with different components of the environment, during which he performs various functions and enters different roles. In this aspect, L. Dobson distinguishes two types of teachers: effective and ineffective. $\mathrm{He}$ points out the following qualities: flexibility, openness, creativity, humor, patience, observation, consciousness (9). A good teacher carries a wide range of professional qualities and his or her effectiveness is influenced by the extent of their manifestation. Ron Clark's studies among the student community about what teachers would like to teach them highlight some significant qualities that students believe their teachers must possess. R. Clark points out that students want to have more exciting teachers, expect teachers to emit more passion and energy, be dynamic, overflow with vitality, be passionate in everything they do, work on themselves, smile more often, and give students optimism (10). An important characteristic of the personality of a good teacher is his or her creative nature. As P. Petrov points out: "The teacher is an immediate creator of the learning process. The fulfillment of pedagogical prescriptions and the compliance with the norms of this activity not only do not stifle the teacher's creativity but are a prerequisite for this. A creative working teacher is not just a user of scientific and pedagogical knowledge, he is not even a rationalizer. Pedagogical creativity requires combining teaching with research, with experimentation, with scientifically applied and implementing activities"(11). As a teacher's professional quality, pedagogical optimism is mentioned. According to I. Shivacheva-Pineda, 'the contemporary Pedagogical Theory as well as Pedagogical and Educational Practice are guided by the principles of humanism and positivism, which further emphasizes the correlation between pedagogical optimism and efficiency of the pedagogical activity (12). Among the significant qualities of a good teacher, the authors also place love for the profession, which closely correlates with the love of the children with whom the teacher performs a pedagogical interaction on a daily basis; a sense of humor, helping the teacher not to dramatize insignificant problems or emergencies and provocations in the learning process. The expression of patience is a quality which can be seen as a key factor for the 
learning success. Pedagogical observation that ensures control over what is happening in the classroom. Conscious attitude of the teacher to his or her professional duties, which implies subject-subject interactions with the learners, Are such qualities characteristic of the Bulgarian teacher's personality? What qualities should the good teacher have according to the students of the pedagogical specialties and according to the practitioners of Bulgarian teachers? These are issues that we will try to answer by presenting the results of this pedagogical study.

\section{RESILTS}

Distribution of the respondents by gender

The results indicate that the gender distribution of the students surveyed is the following: $93.75 \%$ are female and $6.25 \%$ - male. The small percentage of men in the pedagogical specialties confirms the established tendency for the profession of the teacher to become less attractive among male representatives.

The results indicate that $10 \%$ of the surveyed practitioners are male and $90 \%$ are female representatives. We have a pronounced tendency to feminization of the teaching profession in Bulgaria.

\section{Distribution of students by age}

The age distribution of the students covered by the survey is the following: $19-24$ year-olds: $76.56 \%$; 25 - 30 year-olds: $12.50 \%$; 31-36 year-olds: $7.81 \%$; over 36 years of age: $3.13 \%$. From the statistical data recording the age of the students in the pedagogical specialties, it can be concluded that the largest share is held by students who continue their studies at higher education institutions immediately after completing the high school stage.
TENEVA M.

Approximately $77 \%$ of the freshmen included in the study are aged 19-24. The aggregate share of all other students (from 25 years to over 30 years) represents $23.44 \%$. This finding gives reason to believe that the teaching profession is attractive to young people and they are willing to choose to teach different pedagogical specialties at the university after graduating from secondary education.

\section{Distribution of the teachers according to the duration of their pedagogical experience in years}

The teachers surveyed are allocated according to their pedagogical experience (in years) as follows: $1-5$ years: $6.67 \%$; $6-10$ years: $6.67 \%$; $11-15$ years: $13.33 \%$; $16-20$ years: $6.67 \%$; $21-$ 25 years: $16.66 \%$; $26-30$ years: $20 \%$ and over 30 years: $30 \%$. The results indicate a situation in which teachers with pedagogical work experience of 1 to 25 years represent a share of $50 \%$ of all teachers surveyed. The other $50 \%$ is represented by teachers in the last two sectors of the scale, namely those from 26 to 30 years old and over 30 years of pedagogical working experience. While only $6,67 \%$ of the teachers are young people who have between 1 and 5 years of work experience in the field of education, those teachers who practice the profession from 26 to 30 years of age occupy a $50 \%$ share. These data reveal the trend towards aging of people exercising the teaching profession in our country.

\section{Dynamics in diagnosing the qualities of a good teacher}

The dynamics in diagnosing the qualities of a good teacher from the study of students and practising teachers can be ascertained from the data listed in Table 1.

Table 1. Dynamics in diagnosing the qualities of the good teacher

\begin{tabular}{|l|l|}
\hline Students from the pedagogical specialties & Practising teachers \\
\hline 1. Love for the children $-81,25 \%$ & 1. Love for the children $-63,33 \%$ \\
\hline 2. Love for the profession $-64,06 \%$ & 2. Love for the profession $-56,67 \%$ \\
\hline 3. Patience $-42,19 \%$ & $\begin{array}{l}\text { 3. Skillful teaching }-53,33 \% \\
\text { 4. Friendly attitude to the students }-40,63 \%\end{array}$ \\
\hline 5. Equal attitude to all students $-39,06 \%$ & $\begin{array}{l}\text { 5. Ability to involve the students in the work - } \\
40 \%\end{array}$ \\
\hline
\end{tabular}

From the data listed in Table 1. it can be summed up that the rank scale defining the top five positions of the teacher's professional qualities by practising teachers is characterized by a smoothly expressed dynamism. The dynamics between its lowest value $(40.00 \%)$ and its highest value $(63.33 \%)$ is $\mathbf{2 3 . 3 3 \%}$. The scale, which reflects the top five positions of the teacher's professional qualities, ranging from the students of the pedagogical majors, is characterized by a jump of dynamism. The dynamics of its lowest value $(39.06 \%)$ and its highest value $(81.25 \%)$ is expressed in $42.19 \%$. 
The juggling dynamics in the ranking of the teacher's prominent qualities by the students reveals the tendency according to which a large share of the students in the pedagogical specialties is synchronized in their opinion on the significance of the first two qualities. Their share in both cases exceeds $50 \%$, which means that more than half of the students surveyed highlight "love for children" $(81.25 \%)$ and "love for the profession" (64.06\%) as qualities with the highest importance for the teacher. When ranking the other 20 qualities, there are not so many coincidences between individual student charts. There is a tendency of large scattering of the vote (from first to fifth position). The next three qualities, which are placed by the largest number of students in one of the positions 1 to 5 , have gathered the vote of less than half of the students. The third position is the quality of patience with $42.19 \%$. The fourth position is the friendly attitude towards the students with $40.63 \%$. The fifth position is occupied by the "equal attitude towards all students" with $39.06 \%$.

The fluent dynamics in the ranking of teachers' professional qualities by practitioners reveals the trend in which the dispersion of the vote is less pronounced. Coincidences are more often encountered when putting the proposed qualities on the respective positions. Teachers, from the point of view of their practical experience, differentiate more often than the students the same qualities and rank them in the same rankings by degree of importance. Three of the qualities most often posed by teachers in positions 1 through 5 have combined the vote of more than half of the teachers surveyed. The first position is taken by "love for children" - $63.33 \%$. On the second position, "love for the profession" was set with $56.67 \%$. The third position is occupied by "skillful teaching" with $53.33 \%$. The qualities placed in fourth and fifth positions have combined the vote of less than $50 \%$ of practitioners. The fourth position is the quality of "patience", which united the vote of $43.33 \%$ of the teachers. The fifth position is occupied by the teacher's ability to engage students in work, which is preferred by $40 \%$ of practitioners.

The summarized results of Task 1 of the test of the two target groups (students of pedagogical specialties and teachers) reveals correlation dependence in diagnosing three of the ranks of the leading positions, qualities. Students from pedagogical majors and practitioners stand out as professionally important and rank among
TENEVA M.

the top five in the range scale: "love for children", "love for the profession" and "patience".

The results of task 1 of the test indicate a lack of correlation in the opinion of the two target groups regarding two of the qualities that are placed on one of the top five positions in the rank scale of the teacher's prominent qualities. Students take out in leading positions the "friendly attitude of the teacher to the students" and "the equal attitude of the teacher towards all students". Students who have completed a course in pedagogical specialties were in the position of high school students up to months ago. It is difficult for them at this stage to accept the reality that they are the future educators on whom the nation's education will depend. They are not familiar with the nature of the teaching profession and this directs them to a choice of personal rather than professional qualities of the teacher. At fourth place among the significant qualities of the teacher, students put "friendly attitude towards students". At fifth place they rank the "equal attitude towards all students". By choosing these two qualities, students, even in the initial stage of accumulation of their pedagogical competence, consider the fact that in order to be good teachers it is necessary to accept their students as subjects equivalent to themselves, to understand them, to cooperate with them, be honest and fair in their dealings with the students. Teachers (from the point of their pedagogical knowledge and experience) focus on the choice of professional qualities. Among the first five major qualities of the teacher, they rank "the skillful teaching" and "the teacher's ability to engage students in

\section{CONCLUSION}

The results from the performance of Task 1 of the test Diagnosis of Good Teacher Qualities give reason to summarize the following:

$>$ A correlational interdependence between the qualities in the rank scale for the teacher's professional qualities in the pedagogical specialties and the teachers was established. At the first two positions, the tested from both target groups place "love for children" and "love for the profession".

$>$ Among the professionally important qualities of the teacher (between first and fifth position) the two target groups place "patience". Students in pedagogical specialties rank "patience" in third place and teachers rank it in fourth place. 
When differentiating the teacher's first five in-depth qualities, students focus on choosing qualities that nuance the relationship between the subjects in the educational process, such as "friendly attitude towards students" and "equal attitude towards all students".

> Practicing teachers place among the first five in significance the qualities of the teacher that relate directly to their professional activity. Among the qualities of the highest importance, they refer to "skillful teaching", as well as "the ability to involve students in work".

\section{REFERENCES}

1. Vasilev, D. Experimental pedagogy. Sofia: Publishing House "Daniela Hubenova". p. 290, 2008

2. Stamatov, R., Minchev, B. Human psychology. Plovdiv: Publishing House „Hermes”. p. 59, 2005

3. Teneva, M. Who is a good teacher? Stara Zagora: Trakia University, p. 10, 2017

4. Solovjov, A. Professional choice. Moskow: publ. ,Eksmo”, 2013
5. Vasilev, D., Merdjanova, Y. Theory and methodology of professional orientaton. Sofia: University Publisher "St Kliment Ohridski”. p. 20, 2003

6. Klimov, E. A. Psychology of professional self-defining. Moscow: publ. centre "Academia", 2010

7. Andreev, M. Thoughts on education. Sofia: publ. "Iztok - Zapad". p. 118, 2015

8. Olsen, B. How reasons for entry into the profession illuminate teacher identity development. Teacher Education Quarterly, Summer, 2008. http://eric.ed.gov/PDFS/EJ831706.pdf

9. Dobson, L. Effective studying. Sofia: Publishing House "Lik". pp. 40-46, 2006

10.Clark, R. The end of classroom boredom. Sofia: publ. "Iztok - Zapad”. p. 312, 2013

11.Petrov, P. Modern didactics. Sofia: publ. "Avangard Prima". p.157, 2016

12.Shivacheva-Pineda, I. Pedagogical Optimism - Dimension of Professionalism. Pedagogy. Volume 90. Number 2. Sofia: publ. ,Az-buki”. p. 207, 2018 